\title{
LEITURA QUALIFICADA DE ECO-IMAGENS: RACHEL CARSON CENTER PERSPECTIVES ${ }^{1}$
}

\section{QUALIFIED READING OF ECO-IMAGES: RACHEL CARSON CENTER PERSPECTIVES}

\author{
Bruno Vinícius Mützenberg*
}

PARAK, Gisela (Ed.). RCC Perspectives. Eco-Images: Historical Views and Political Strategies. Munich: RCC Perspectives, 2013, n. 1.

O Rachel Carson Center (RCC) é um proeminente centro de pesquisas e divulgação científica em História Ambiental sediado em München, Alemanha. Fundado em 2009 em iniciativa conjunta da Ludwig-Maximilians-Universität (LMU) e do Deutsches Museum, leva um nome condizente com sua proposta e atuação. Rachel Louise Carson foi uma importante bióloga, zoóloga e ambientalista, chamando atenção mundial à causa ambiental muito antes da dispersão dessas ideias por associações internacionais e pela mídia. Em 1962, publicou Silent Spring, referência em movimentos e estudos ambientalistas. ${ }^{2}$

Além de organizar e apoiar eventos ligados a estudos ambientais e publicar livros do tema, um dos principais meios de divulgação utilizado pelo RCC é seu periódico $R C C$ Perspectives, com número variável de temáticas anuais. O primeiro de 2013 foi intitulado "Eco-Images: Historical Views and Political Strategies", disponível no endereço eletrônico da instituição. Editado por Gisela Parak, Historiadora da Arte pela LMU, a edição conta com seis artigos relacionados ao uso de imagens em debates, disputas, e campanhas ambientais, constituindo as então chamadas "eco-imagens". Todos os autores foram coerentes na proposta da organização, embora cada qual tenha focado em temática afim a sua área de pesquisa.

\footnotetext{
* Mestrando no Programa de Pós-Graduação em História da Universidade Federal de Santa Catarina (UFSC) e bolsista CAPES. E-mail: brunomutz@hotmail.com
} 
$\mathrm{Na}$ introdução os objetivos foram explanados de forma concisa e clara, apontando os alcances e a intensidade conquistáveis na utilização de imagens. Diferentemente dos textos escritos, que, apesar de guardarem possibilidade de interpretação e de diferentes leituras de acordo com a bagagem cultural de cada leitor, são constituídas de palavras exatas, as imagens não podem ser medidas ou contabilizadas, pois que seus sentidos são vislumbrados diferentemente. Esse aspecto poderia ter sido melhor comentado na introdução, mas foi explorado adequadamente no artigo do prof. Paolo Peverini, ensinante de Semiótica e Semiótica Visual em Roma, além de mais detidos comentários da própria organizadora. Ela citou, por exemplo, o conceito de iconicidade, embora não o tenha explicado satisfatoriamente. Por outro lado, esclareceu que imagens da natureza são por vezes tidas como eco-imagens, amiúde não as sendo. O conceito adequadamente adotado por Parak foi de "imagens decisivamente informadas por uma agenda ambiental". ${ }^{3}$ Ou seja, fotografias ou ilustrações de paisagens, quando apenas utilizadas para ilustrar, não se enquadrariam.

"Our Only World": An American Vision foi o artigo de Gisela Parak escrito para o RCC Perspectives 2013/1, e tratou da simultaneamente intensa e duradoura campanha dos EUA para moldar sua própria imagem no contexto ambientalista internacional. O objeto do trabalho, ampla exposição e publicação de fotos, serviu como estudo de caso para a postura e a estratégia do governo estadunidense para constituir uma imagem ambientalmente protagonista durante o mandato Nixon. A mostra "Our Only World" foi composta de 113 imagens de poluição ambiental, realizando tour de exibição pelos Estados Unidos. As fotografias selecionadas pela autora traduziram bem as características da exposição: boa qualidade de imagens, incluindo cores vivas e edição chamativa, e cenários um tanto sensacionalistas. Mais tarde, a exibição a Tókio, com fins de participar do World Environment Exhibition, e assim promover a imagem dos EUA como portadores de visão transnacional. A autora bem observou, no entanto, o caráter nacional das fotos: exclusivamente "americanas". Parak foi adequadamente mais longe, interpretando o ato como condizente à visão de mundo dos EUA: um mundo 'americano'. Não só teriam os EUA a missão de liderar o planeta na missão de salvar o meio-ambiente, mas teriam que começar em casa, onde a natureza mundial estava representada, bastando aquela seleção de fotos para exprimir a poluição global.

O termo "spaceship Earth" era repetidamente utilizado no contexto governamental ao redor de Nixon. A autora afirmou que os representantes do governo recorriam a essa e outras expressões mobilizadoras da ideia de uma missão humanitária pela Espaçonave Terra, elencando habilmente historiografia e literatura relacionadas. A análise política foi frequentemente bem executada, assim como nos artigos de Erika Bsumek e Oluwafemi A. Ladapo. Os demais autores reservaram-se mais às questões locais e/ou estratégicas no uso de imagens. Ainda no caso da exposição Our Only World, Parak comentou a 
publicação do livro Only One Earth: The Care and Maintenance of a Small Planet, cujo título se tornara slogan da exposição. Segundo ela, o livro contribuiu para formar a crítica pós-guerra da ciência e da tecnologia da Guerra Fria, bem como da visão neoimperialista que separou o mundo em países desenvolvidos e "em desenvolvimento." No entanto, ela foi deveras contida em sua observação, pois poderia ter explorado minimamente as dificuldades em superar tal separação no recorte temporal estudado, bem como os limites políticos da proposta holística de que "tudo está conectado", esbarrando as propostas ambientais em fronteiras de estado.

A vontade política de liderar o mundo nessa 'cruzada verde', expressa em encontros das Nações Unidas, estaria sendo boicotada no próprio território, com leis ambientais estagnadas por políticos que viam como inquestionável o direito dos estadunidenses de consumir o quanto desejassem. Assim, Nixon tornava a ser o típico governante liberal que privilegiava a criação de empregos sempre que estes supostamente entrassem em confronto com o preservacionismo. Foi observado que os EUA foram didáticos em sua campanha, mas não inovaram. Permaneceram no "denominador comum", sem discutir os (então) novos conceitos de "scientific ethics" e "science of civilization". Gisela fez bom uso de imagens ao relacioná-las à sua explanação, o que foi menos explorado nos artigos de Ladapo e de Peverini. Este, que claramente domina os conceitos de semiótica, selecionou poucas imagens para ilustrar seu discurso, o que dificulta a compreensão a leitores menos instrumentalizados. Ladapo reproduziu várias charges que, no entanto, não foram tão esclarecedoras de sua abordagem.

Oluwafemi Alexander Ladapo, PHD em estudos de paz e conflito pela Universidade de Ibadan, Nigéria; e Paolo Peverini, professor de semiótica, apresentaram resultados de estudos mais politicamente orientados. O primeiro selecionou um caso particularmente polêmico, além de vergonhoso para os culpados. Estudantes nigerianos na Itália descobriram que o país onde residiam enviava lixo regularmente à cidade de Koko, na Nigéria. Em jornais, a notícia gerou séries de charges envolvendo a polêmica, sendo estas trabalhadas pelo autor. O prof. Peverini selecionou um caso mais 'leve', o uso de eco-imagens por organizações ambientalistas em disputas públicas por reconhecimento de legitimidade.

Apesar dessa gradação, Ladapo não extraiu toda a atratividade que seu recorte parece oferecer, tendo resultado assim em texto demasiado descritivo, que almejava reunir quantidade suficiente de detalhes para ilustrar o processo. Apesar dos temas de cartoons terem sido bem selecionados, páginas foram investidas na classificação dos quadrinhos em categorias; que apesar de indispensáveis à pesquisa, teriam proveitosamente cedido lugar para melhores articulação e problematização textuais, certamente necessárias e não esgotadas. O tom político do autor e sua conceituação de eco-imagens, relacionando então com "eco-cartoons", deixaram entrever questões não exploradas, enquanto 
abundaram detalhes metodológicos. Paolo Peverini selecionou um tema mais descontraído, o que não implica em menor relevância. Pelo contrário, pareceu ter sido estratégia didática para facilitar o trabalho de conceitos um tanto abstratos, tais como "aestheticization", "greenwashing", "camouflage", "trompe l'oeil", "mise en scéne", bem como estratégias empregadas através das eco-imagens, como surrealismo, humor negro, paradoxos visuais, shock apeal, entre outros.

O tom descritivo de Oluwafemi Ladapo parece ter sido intrínseco à quantidade de materiais pesquisados. Decidindo por expô-los, mesmo que resumidamente, adotou um tom relatorial. O leitor foi informado, por exemplo, da ocorrência de cartoons relacionados ao lixo tóxico nos jornais "Guardian", "Republic", "Sketch", e "Tribune”; e da classificação em "Law and Policy", "Critical of the Government", "Used to Highlight Other Issues", "Humorous", "Critical of Foreigners", ou "Informative". Demonstrou sólidas conclusões e rigor no tratamento às fontes, mas resguardou seu posicionamento para a conclusão do artigo. Sagazes abordagens sobre corrupção policial, despertamento de críticas adversas pela questão ambiental, como a aversão aos estrangeiros, e a questão exposta em quadrinhos de que a junta militar estivesse mais preocupada com a polêmica do lixo do que com a população, foram apenas pontuadas. Aspectos como a relativamente elevada eficácia das imagens para um público com alto grau de analfabetismo também seriam fortuitamente desenvolvidas.

As disputas entre Greenpeace e Volkswagen, e as campanhas da WWF não limitaram o alcance do olhar de Peverini, pois seus objetos foram apenas apoio para questões como as estratégias de representação e renegociação de significados no debate ambiental. A análise foi de fato "sócio-semiótica", pois analisou a atribuição de significados nas e pelas imagens, de maneira interconectada com as relações sociais entre empresas, instituições, ativistas, e público (papéis não fixos, mas também (re)negociados). Um conceito chave foi "greenwashing", campanha de convencimento público de que determinada empresa seria sustentável, ou prática de "lavar" ambientalmente sua imagem (referência a lavagem de dinheiro). As empresas assim atuariam em campanhas pseudo-ambientalistas, ou mesmo de efeitos irrisórios se comparados aos impactos ambientais causados. No processo, o autor evidenciou a apropriação pelas corporações das imagens reconhecidas pelo público como "ambientais". Foi exposto como, depois de um tempo em circulação, as eco-imagens se tornam símbolos ou ícones por si mesmas, desvencilhando-se (ou não) dos referenciais originais e se tornando os próprios significantes dos significados ora incorporados. Assim, basta às empresas candidatas a uma imagem "mais verde" utilizarem símbolos clássicos de animais, paisagens, ou árvores, ou mesmo adotar a cor verde em seu logotipo.

Em outro artigo da edição, intitulado "Advertising the Environmental Movement: Vickers and Benson's Branding of Pollution Probe", Ryan O'Connor 
demonstrou como a apropriação de discursos ocorreu em disputas ambientais envolvendo o Pollution Probe, organização ativista de importância central no Canadá. Em um dos casos, o grupo fez uma forte campanha para denunciar a poluição gerada pelas chaminés de uma grande fábrica. Ao terem como resposta a proposta da usina de trocar as chaminés por uma "super-chaminé", que liberaria os gases muito acima da cidade, não atingindo os moradores próximos, e supostamente sendo "limpa" por dispersão dos ventos; os autores dos panfletos se utilizaram da proposta em charge, ridicularizando-a com o uso de ilustração irônica.

Para enfrentar tanto a apropriação das eco-imagens por empresas, quanto por governos, que também demandam imagem ambientalmente correta, os ativistas desenvolveram diversas estratégias inovadoras na luta por legitimidade, ou contra a legitimidade dos adversários. Esse tipo de atuação, marcado por poucos recursos, muita criatividade, e descentralismo de liderança é denominado pelo autor como "ação de guerrilha". Nesse cenário, uma estratégia amplamente utilizada pelos "guerrilheiros" seria infectar o sistema como um vírus: plantar ideias chamativas e significativas nos discursos da população por meio de campanhas não convencionais, com a utilização de surrealismo, humor negro, e paradoxos visuais em imagens nas ruas, em panfletos, ou outros suportes. Peverini afirma ter se tornado cada vez mais difícil às empresas "lavar" suas imagens frente a um grupo progressivamente melhor informado, que buscaria informações em outras fontes. Tudo indica ser fato consumado, mas o autor poderia ter problematizado brevemente a suposição, por não ser óbvia essa suposta qualificação de público. Esse público seria justamente o mais receptivo às estratégias inovadoras dos ativistas, no entanto, o que reforçaria a confiabilidade da afirmação anterior. Além disso, é possível apreender do texto que as crescentes tentativas de "greenwashing" traduzem maior exigência do público. Os argumentos estão presentes, apenas não tendo sido elencados pelo autor para corroborar a afirmativa em questão.

Foi bem explanado como a midiatização da crise ecológica levou a uma perda de significado das eco-imagens, transformando-as mais ainda em símbolos e ícones. Nesse contexto, as campanhas tradicionais de argumentação direta sobre realidades com o uso de imagens fortes e apelo emotivo perderam eficácia. Assim, as empresas intensificaram seu marketing e os ativistas trocaram o apelo ao medo (fear-appeal) pela prevenção, que consiste em focar a atenção com retórica visual ou verbal, e em seguida informar através de imagens do problema, suas causas e soluções propostas. O autor utilizou exemplos como uma piscina em trompe l'oeil (pintura com profundidade ilusória) apresentando cidade submersa, e o discreto endereço eletrônico na borda da piscina. Ironia também é utilizada na fórmula discursiva "alerta, sugestão, condenação". Outro recurso é o "stickering": grandes imagens chamativas recortadas de sua origem e coladas em contexto urbano, como uma nuvem de fumaça artificial gigante (à moda de desenhos animados) presa ao escapamento de um 
automóvel real. A tática alerta mais que campanhas tradicionais, realizando "subversão semântica dos espaços", modalidade de ação largamente utilizada na abordagem "de guerrilha", apropriação de espaço público e transformação de sentido via intervenções.

A escrita do autor foi ao encontro de algumas características desse novo ativismo, ao comunicar muito em poucas linhas, transmitindo as ideias sem volumosos exemplos. Ainda quanto aos ativistas, explicou a valorização do marketing "boca-a-boca", o empoderamento dos indivíduos ao chamá-los à ação, o uso caricato de estereótipos do ativismo "tradicional", e o intuito de gerar reação em cadeia das ideias na internet. Nos dois exemplos centrais de sua contribuição, foram boas escolhas para tratar das estratégias de instituições não governamentais de proteção ao meio-ambiente. Além de comentar a batalha travada pelo Greenpeace à Volkswagen, apresentou a campanha da WWF, que usou o próprio logotipo do urso panda em tática inovadora: fazê-lo sumir gradativamente de uma placa a outra, até o completo desaparecimento, dispensando legendas. Assim, o autor demonstrou como a ausência de palavras pode implicar maior significado atribuído à imagem, em processo de mimesis, a utilização de um lugar-comum para despertar um segundo nível de discurso.

Ryan O'Connor, Robin Kelsey (Sierra Club Photograghy and the Exclusive Property of Vision), e Erika Bsumek (Imagining Indians and Revisiting Reclamation Debates) contribuíram com estudos mais sociais, com menos análise pictórica. O'Connor, PHD pela University of Western Ontario, examinou uma campanha impressa no Toronto Telegram, que teria dado origem ao Pollution Probe. O grupo instigava o empoderamento do público através do uso inteligente de imagens como charges críticas à poluição do Don River e à proposta de construção da Ontario Hydro. Na mesma linha dissertativa foi exposta a atuação do Sierra Club em defesa do Dinossaur National Monument, por Robin Kelsey, professor de fotografia em Harvard; em esclarecedora explicação semântica, que seria mais proveitosa com a localização e a contextualização do monumento defendido pelo Sierra Club. O autor relacionou o renovado ímpeto de explorar economicamente o oeste com a histórica "marcha para o oeste" dos desbravadores. Enquanto Ryan O'Connor viu no caso Pollution Probe um diálogo próximo ao público, talvez por serem estudantes envolvidos na realidade local, almejando empoderamento popular; Kelsey explorou o aspecto propagandístico da campanha do Sierra Club. O clube publicou um livro de fotos exaltando a natureza e um calendário. Para ambos os casos, o autor apresentou falas reconhecedoras do caráter apelativo, em lógica de fé.

Mantendo a prevalência do olhar político, O’Connor atestou que as eco-imagens são necessariamente políticas, mas que os membros do Pollution Probe não eram necessariamente contra empresas e corporações, mas contra danos ao meio-ambiente. Destacou também a valorização da ação individual 
no grupo, que solicitava envio de cartas aos governantes, e a combatividade do grupo às estratégias de adversárias. Kelsey, diferentemente, apresentou visões antagônicas, uma que via a ciência como aliada da preservação ambiental através do progresso das técnicas e do conhecimento, e outra que a via como o motivo das crescentes agressões à natureza. Natureza essa representada de forma seletiva nas fotografias, o que o autor bem demonstrou. Ele comentou como determinadas paisagens, que deveriam se mostrar intocadas, mas possuíam marcas visíveis de intervenção humana, eram fotografadas em proximidade e em determinado ângulo, enfocando apenas os campos e florestas "virgens".

Erika Bsumek, professora da University of Texas, focou seu estudo na apropriação simbólica dos indígenas Navajo pelo movimento contra a construção de uma usina hidrelétrica no Colorado (Colorado River Storage Project Act - 1956). O aspecto mais curioso na argumentação foi a apresentação de três lados discordantes na contenda, o governo, com a proposta de barragem, os ativistas contra a construção da mesma, e os Navajos, que são apropriados tanto por governo quanto por ativistas em suas campanhas de convencimento. Ela apresentou de um lado a construção da imagem do "environmental indian", protetor natural do meio-ambiente, e de outro sua ilustração (havendo, de fato, uma pintura) como seres necessitados da ajuda do homem branco, carentes de civilização.

Vários foram os artifícios empregados de ambos os lados (brancos) da polêmica para 'pintar' os nativos com as suas cores. Entre os argumentos positivados pró-represa, está o "melhoramento dos Navajos", progresso que seria proporcionado à região, melhorando o nível de vida. Foram utilizadas imagens mais voltadas à população dos EUA do que aos Navajo, pois que esses, transparece a autora, formavam sua própria opinião. Se inicialmente eram bastante resistentes à ideia de uma represa em suas terras, as novas gerações de nativos estavam bastante empolgadas com o adventício de uma substancial fonte de renda, inclusive tendo contribuído com grandes doações espontâneas para a conclusão da obra. Os ativistas, que iniciaram suas campanhas sem se dar conta da devida importância dos Navajos no debate, passaram por um processo de descoberta e resignificação dos indígenas como possíveis aliados na disputa. As eco-imagens foram centrais para apresentá-los como anti-represa, ilustrando-os como antigos protetores da terra, em postura anticapitalista e antiprogressista.

$\mathrm{Na}$ explicação do processo, a autora reconheceu a limitação de suas conclusões pelas fontes, sempre parciais, e fez interessante comparação entre as imagens selecionadas, indicando a movimentação dos personagens das fotos se "distanciando" do expectador em uma pintura, em fuga, e parados em outra, observando o que ocorre. Essa postura foi quase equânime no grupo de autores da edição, demonstrando alinhamento teórico. Embora tenha havido maior valorização de aspectos sociais, políticos, ou pictóricos em cada um deles, nenhum aspecto foi ignorado por nenhum dos contribuintes. Bsumek e 
Ladapo explicaram os usos das eco-imagens como ferramenta política. Peverini utilizou casos de disputas para permitir sua análise semiótica, também efetuada por Robin Kelsey. O volume se mostrou coerente dentro de suas diferentes abordagens, explicando eco-imagens por vários caminhos.

\section{NOTAS}

${ }^{1}$ PARAK, Gisela (Ed.). RCC Perspectives. Eco-Images: Historical Views and Political Strategies. Cidade: RCC Perspectives, 2013, n. 1.

${ }^{2}$ CARSON, Rachel Louise. Silent Spring. Boston: Houghton Mifflin, 1962.

${ }^{3}$ Todas as traduções são próprias e de responsabilidade do autor.

Resenha recebida em setembro de 2013. Aceita em julho de 2014. 